\title{
REVIEW ON: STUDY ON PROPERTIES OF CONCRETE BY USING BAGASSE ASH AND SAW DUST ASH WITH VARIOUS PROPORTIONS
}

\author{
Priya S. Chaware \\ M.tech Student of Civil Engineering Department, \\ K.D.K. College of Engineering, Nagpur, Maharashtra, India \\ Dr. Valsson Varghesse \\ HOD \& prof of Civil Engineering Department, \\ K.D.K. College of Engineering, Nagpur, Maharashtra, India
}

\begin{abstract}
A review is presented based on effect of using agricultural waste like Baggase as and Saw dust ash on concrete by replacing cement with it at different proportions. Cement which plays important role as construction material. Concrete use as structural material which have certain limits in case of strength, durability, ductility etc. Baggasse ash from sugar industry and Saw dust ash from saw mills and other sources can be re-used as cementitious material due its chemical property. It helps to improve the quality and strength of concrete, In this paper studies shall be conducted on strength of concrete for M25 grade for various sets of replacement ranges from $10 \%$ to $40 \%$ and number of tests are conduct for several curing days i.e.7,14,28 check out affect on mechanical properties of concrete. Finally conventional concrete obtained results compare with concrete blended with above two type of waste.
\end{abstract}

Key words: Concrete, Agricultural waste, Baggase ash, Saw dust ash, Conventional concrete.

\section{INTRODUCTION}

The world of construction industry is difficult to imagine without cement. Shelter, food and clothes are the basic essential needs of human beings which are automatically fulfilled by the nature itself on a large percentage except shelter. Now a days there is need for affordable building material to carry out construction work. Utilization of different supplementary cementitious materials for the production of blended cements contributes to achieving durable and sustainable concrete India is largest agricultural country, rather than throwing it as waste product we can use this agricultural waste as economical cementitious material for replacement of cement.

As the world wide population increase continuously, cost of each basic tings increase rapidly specially building material, due to change in lifestyle and adaptation of modern techniques. As we all know India is one of the large agricultural country in the world. The whole economy and development ratio is depends on agricultural production. Every year millions tones of agricultural waste is generated in every part of our country rather than throwing them as a waste product we can reuse it as a effective and economical substitute. Agricultural waste like Saw dust ash and Bagasse ash have cementitious property so we can easily use this product in manufacturing concrete ingredient like cement.

Bagasse Ash is obtained by burning the bagasse of sugar cane after exerting sugar juice from it. India is largest manufactor of sugar cane in the world and produces 300 million tone per year. To avoid the excess generation of waste and to use it effectively in economical way bagasse ash is used fuel, Raw bagasse ash has a large practical size and a high porosity so it contain more water contain in a concrete mix.

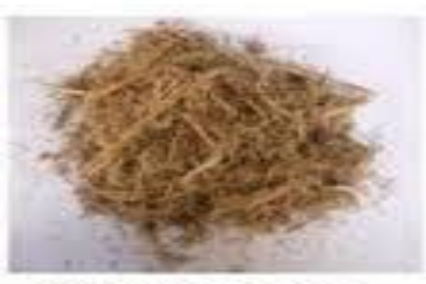

Sugarcane Bagasse

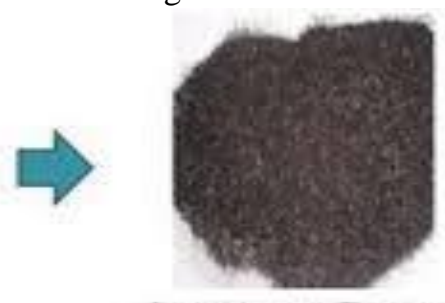

Sagarecane Bagasse ish

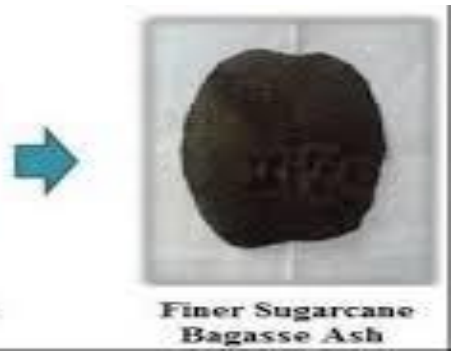

Fig(1): Bagasse Ash 340 
Saw dust is produced from wood working operation such as sawing, milling. It contain fine particles of wood. It's ash is obtained by burning the saw dust wood by heating it at a particular temperature. Saw dust ash is economical and can be effectively use to avoid the environmental hazards. It used in a cement production which possess environmental friendly feature.

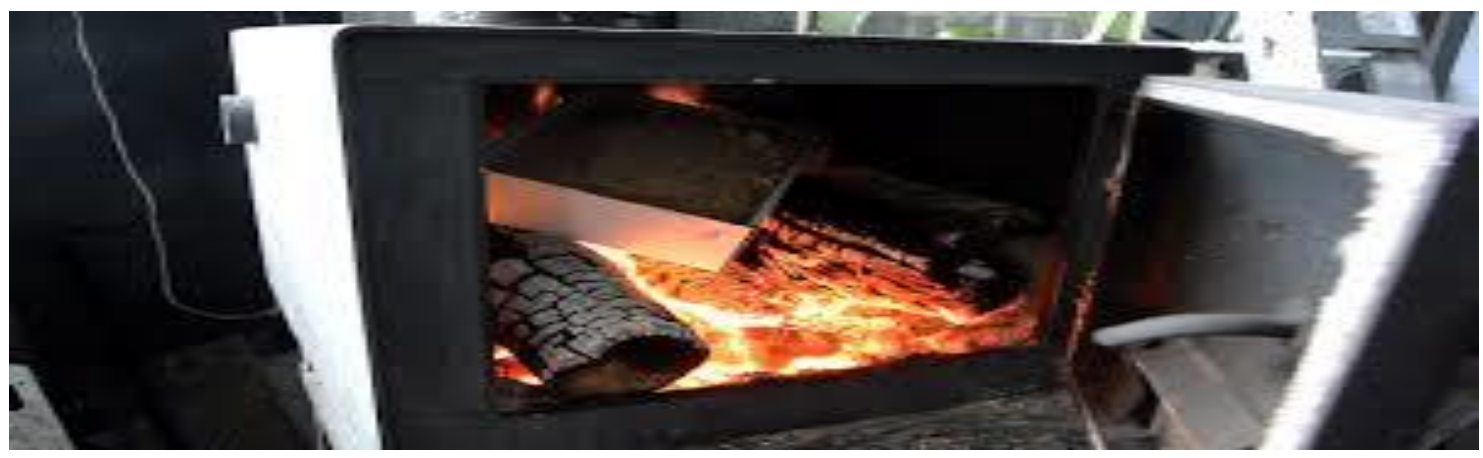

Fig(2):Saw dust ash

\section{RESEARCH DEVELOPMENT}

\section{(A)Saw dust Ash}

Augustine U. Elinwa et al.(2007) Result reported in this paper show that SDA can be used as powder material with cement and super-plasticizers to obtain flow able concrete. It can be perceived workability ranges around characteristic value for self-compaction of $665 / 680 \mathrm{~mm}$ and flow time of $8.2 / 8.4 \mathrm{~s}$ for NS and MS, respectively, of the concrete and the place ability of the as recommended by EFNARC. The compressive strength development of SCC mortar shows a tremendous improvement over the control At 90 days, foremost strength was recorded at $10 \mathrm{wt} \%$ replacement and this is approximately $30 \%$ above the value of control. The study of compressive strength of cubes and microstructure were undertaken for different curing days $3,7,28,60$ and 90. SDA can defer reaction of cement hydration and prolong the setting time of cement paste.

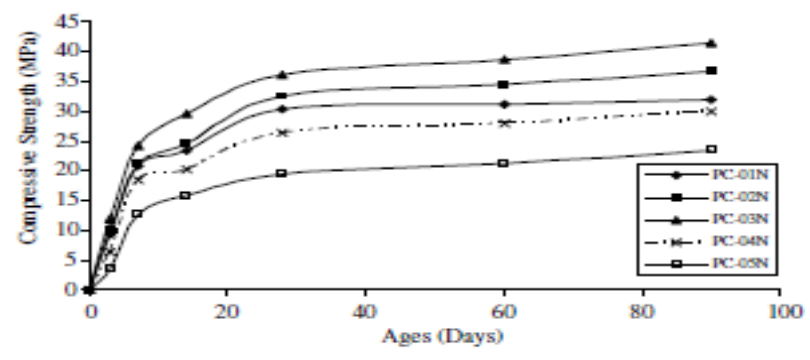

Fig. 2. Compressive strength (curing efiect).
Cheah Chee Ban(2011) This paper presents an overview of the work carried out by the use of wood waste ash as partism replacement of cement in mortar and concrete mixes with incorporation of wood it as a partial cement replacement material in the formulation of concrete mix reduces mechanical strength (compressive, flexural and splitting tensile strength) of concrete. However, there were promising observations that inclusion of wood ash at low levels of cement replacement actually contributed towards the enhancement of compressive strength in concrete mixtures produced. Wood ash use as a partial replacement for OPC at replacement levels up to $10 \%$ by total binder weight can produce structural grade concrete or mortar with acceptable strength properties. Increasing its content formulate concrete mixtures generally results in expanding of water absorption in concrete mixtures. Partial substitution of cement in concrete mixtures at replacement levels up to $25 \%$ by total binder weight does not have adverse effects on the resistance of concrete. 
International Journal of Engineering Applied Sciences and Technology, 2020

Vol. 5, Issue 3, ISSN No. 2455-2143, Pages 340-344

Published Online July 2020 in IJEAST (http://www.ijeast.com)

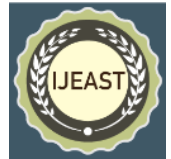

Mix proportion and workability of SCM mixes (Elinwa et aL, 2008).

\begin{tabular}{llcllllll}
\hline Mix no. & Cement $\left(\mathrm{kg} / \mathrm{m}^{3}\right)$ & SDA, $\mathrm{x}\left(\mathrm{kg} / \mathrm{m}^{3}\right)$ & Sand $\left(\mathrm{kg} / \mathrm{m}^{3}\right)$ & Water $\left(\mathrm{kg} / \mathrm{m}^{3}\right)$ & SP dosage $(x)$ & w/c & Mortar spread (cm) & Flow time $(\mathrm{s})$ \\
\hline PC-01M & 441 & $0(0)$ & 662 & 265 & 2.5 & 0.6 & 27 & 4 \\
PC-02M & 419 & $5(22)$ & 662 & 265 & 2.5 & 0.6 & 25 & 7 \\
PC-03M & 397 & $10(44)$ & 662 & 265 & 2.5 & 0.6 & 24 & 7 \\
PC-04M & 375 & $15(66)$ & 662 & 265 & 2.5 & 0.6 & 23 & 12 \\
PC-05M & 353 & $20(88)$ & 662 & 265 & 2.5 & 0.6 & 20 & 18 \\
\hline
\end{tabular}

A.A. Raheem et al (2012) investigated the physical properties and chemical composition of saw dust ash compressive strength and workability property of concrete were obtain by replacing $5 \%, 10 \%, 15 \%, 20 \%$ and $25 \%$ by weight of ordinary Portland cement. Slump and compacting factor test were escorted on fresh concrete and compressive strength test harden concrete. The concrete cubes were tested for different curing days 3,7, 28, 56 and 90 days. It was concluded SDA is good pozzolanic material, as percentage of SDA replacement extent compressive strength and concrete became less workable but drastically it improves strength upto 90 days curing An optimum value of $23.6 \mathrm{~N} / \mathrm{mm} 2$ at 90 days curing showed good output by replacing ordinary Portland cement with 5\% replacement of SDA and it gives maximum strength gain. Hence it proved SDA is ethical pozzolanic material for cement replacement and economical concrete can be secure.

Oblied,I.Q (2014) This paper presents out turn of Saw Dust Ash (SDA) as skewed replacement for Ordinary Portland Cement (OPC) in concrete. SDA was used to replace OPC by weight from 0 to $30 \%$ in steps of $5 \%$. Compacting factor test was carried out on fresh concrete while compressive strength test was carried out on $150 \mathrm{~mm}$ concrete cubes after 7, 14 and 28 days curing in water. The results revealed that the Compacting factor decreased as the percentage replacement of OPC with SDA increased. The compressive strength of the hardened c strength and durability be carried out to ascertain more facts about the suitability of the use of SDA as a pozzolan in concrete. The optimum level of replacement of cement by SDA is in range $0-15 \%$. Bulk densities and Compressive strength lowered with increase in SDA ritual.

Mohammad Iqbal Malik (2015) In this paper, the issues of environmental and economic concern are addressed by the use of saw dust ash as partial replacement of cement in concrete. Cement was replaced by Saw Dust Ash as 5\%, 10\%, 15\% and $20 \%$ by weight for M-25 mix. The concrete specimens were tested for compressive strength, durability (water absorption) and density at 28 days of age and the results obtained were compared with conventional concrete. The results concluded the permissibility of using Saw Dust Ash as partial replacement of cement up to $10 \%$ by weight for particle size of range 90micron. The compressive strength generally increases with curing period and decreases with increased amount of SDA. Only 10\% substitution is allowed at maximum and 5\% renewal is requisite to enjoy maximum well being of strength attain.

Raheem Akeem Aylinde et al (2017) Author investigated the application of Saw dust ash (SDA) as partial substitute for ordinary Portland cement (OPC) in the production of interlocking paving stones, the results designate that SDA is good pozzolan having required standards. The compressive strength of the samples with substitution levels ranging from 5 to $25 \%$ cured for 3-56 days, was lower at initial curing period but improved significantly at later days. 5\% substitution level showed rise in strength compared to 0\% SDA paving stones regardless of curing period. Density decreased with increasing ash content, whereas water absorption increased with SDA content. Such paving stones made with 5\% SDA replacement is therefore recommended for use in the building, especially in residential driveway and walkways.

Hardik Dhull(2017)Studied about saw dust ash prepared from uncontrolled burning of saw dust is evalualated for partial cement replacement in concrete. The strength parameters i.e. compressive strength of concrete with blended saw dust ash and replaced cement by 5\%,10\%,15\%,20\% by wt. to OPC Slump Test was carried out on fresh concrete \& compressive strength test was carried out on hardened concrete. Several cubes were tested at 7 and 28 day. The result showed that saw dust ash is good replacement material for cement with $\mathrm{SiO2}$, $\mathrm{Al} 2 \mathrm{O} 3 \& \mathrm{Fe} 2 \mathrm{O} 3$ of $72 \%$. The slump value decreased with increase in saw dust ash. The compressive strength increased up to $10 \%$ SDA content and then decreased with increase in SDA content.

\section{B) Baggase Ash}

K. Ganesan et al(2007) researcher deliberate the characteristic properties of concrete inclusive of compressive strength, split tensile strength, water absorption property and permeability characteristics etc. Test result indicate that up to $20 \%$ of ordinary Portland cement can be optimally get interchange with well burnt sugarcane BA without any adverse effect on desirable properties of concrete which shown result in development of high strength concrete accompanying reduction in water content and above all observations have direct bearing on durability of concrete structure.

G.C. Cordeiro et al(JAN 2008) paper explore pozzolanic and filter effect of a residual SCBA in mortar established from the 
comparison of with an insoluble material at the same packing density. After 28 curing days, the compressive strength of SCBA mortar was $31 \%$ higher than the strength mixture. The result recommend that SCBA present physic-chemical properties appropriate for its use as mineral admixture and its reactivity was mainly dependent on particle size and fineness of cement particles.

Nuntachai Chusilp et al (June 2009) The result revealed at the age of 28 days curing , the concrete sample containing 10-30\% ground BA by weight of binder had significant compressive strength than ordinary concrete. Concrete having $30 \%$ ground bagasse ash had a higher compressive strength along with lower water permeability than the control concrete, both at ages of 28 and 90 days. The optimum Cement replacement fraction by ground bagasse ash was $20 \%$ by wt of binder. A higher replacement proportion $(30 \%)$ resulted in concrete with lower water permeability.

Sumrerng Rukzon et al (Aug 2011) Investigate use of Bagasse ash as a pozzolanic material for producing high strength concrete. The test results indicated integration of BA up to $30 \%$ replacement level increases the resistance to chloride penetration. Besides the use of $10 \%$ of BA produced concrete with good strength and low porosity. Reasonably substitution of $30 \% \mathrm{BA}$ is admissible for procuring high strength concrete.

A. Bahurudeen et al (2014) In this study, SCBA blended cement with separate level of replacement in characterized in systematic manner and conclusion drawn that concrete with BA replacement indicate result tat concrete with same grade can be make with up to $25 \%$ replacement of cement by SCBA. Heat of hydration of concrete containing SCBA based cement with $10 \%$ and $20 \%$ replacement was studied using adiabatic calorimetry. Result of comprehensive evaluation of mechanical and durability characteristics suggest that SCBA can be used as cement replacement in blends up to $25 \%$ to obtained good quality concrete.

A.Rajasekar et al (2017) Paper demonstrate feasibility of utilizing SCBA as pozzolanic material in production of ultra high strength concrete and replacement dosage varied from $5 \%$ to $20 \%$ by weight of cement, incorporation of BA improves the workability, compressive strength and decrease the rate of water absorption. Result indicate that concrete mix with $15 \%$ cement replacement exhibited a superior performance in all tests. Optimum replacement ratio of $15 \%$ yielded better performance without having any adverse effect on hardened concrete. Convincingly $20 \%$ substitution of SCBA is decent to produced concrete.

P.Jagadesh et al (2017) In this paper author concluded link between cylindrical compressive strength and density is found to be directly proportional irrespective of nature of curing period for SCBA blended concrete. Cylindrical compressive strength shows enhanced strength is about $28 \%$ compared to control for $10 \%$ of cement amount.

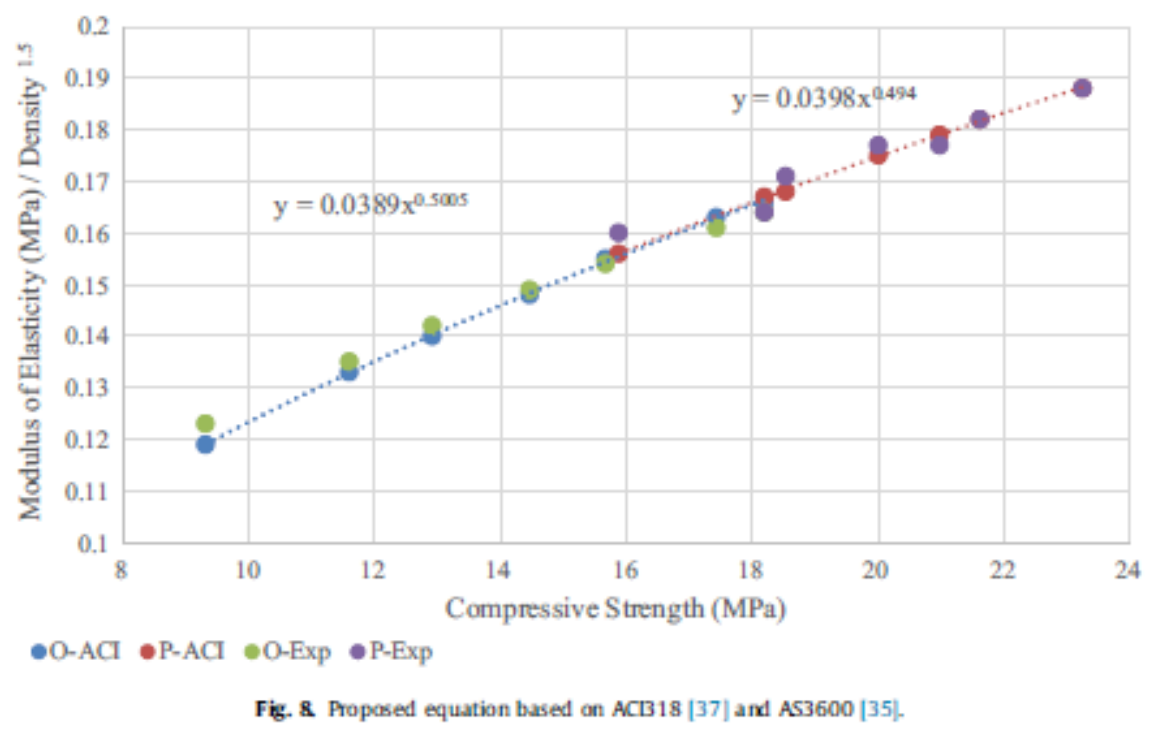

Seyed Alireza Zareei et al (2018) This paper present investigation on $\mathrm{BA}$, as it partially renewal cement, light weight and self compacting concrete. The compressive and tensile strength tests result indicated that 5\% SCBA content improved the strength properties of ordinary and light weight concrete. In corporation with that amount of replacement, concrete led to an increase in the impact resistance by $50 \%$. 


\section{CONCLUSION}

After reviewing papers of various researchers, it is discern that substitution of cement up to $30 \%$ combine with agricultural waste provide effective result in obtaining good quality of concrete in a economical way. Most of the researchers concluded that BA and SDA used as a pozzolanic material in concrete with an acceptable compressive strength, split tensile strength, flexural strength. It also helps to reduced water permeability with respect to conventional concrete. Most of the researchers also noticed that incorporation of BA and SDA partially replace cement up to certain extent improved durability and workability of concrete.

\section{ACKNOWLEDGEMENT}

I like to thanks my guide prof. Dr. Valsson Vargesse and Co guide Mr Anshul Nikade who helps to choose this project topic and provide all the detailed information regarding to carry out project work which helps me to enhance my knowledge related to various aspects of concrete industry and also effective use of this agricultural waste to obtained economical concrete.

\section{REFERENCES}

[1] S. Rukzon, P. Chindaprasirt, Utilization of bagasse ash in high-strength concrete, Mater. Des. 34 (2012) 45-50.

[2] A. Bahurudeen, M. Santhanam, Influence of different processing methods on the pozzolanic performance of sugarcane bagasse ash, Cem. Concr. Compos. 56(2015) 3245.

[3] N.B. Singh, V.D. Singh, S. Rai, Hydration of bagasse ashblended Portland cement, Cem. Concr. Res. 30 (2000) 14851488.

[4] K. Ganesan, K. Rajagopal, K. Thangavel, Evaluation of bagasse ash as supplementary cementitious material, Cem. Concr. Compos. 29 (2007) 515-524.

[5] H. Zanni, M. Cheyrezy, V. Maret, S. Philippot, P. Nieto, Investigation of hydration and pozzolanic reaction in reactive powder concrete (RPC) using 29Si NMR, Cem. Concr. Res. 26 (1996) 93-100.

[6] O. Bayard, O. Plé, Fracture mechanics of reactive powder concrete: Material modeling and experimental investigations, Eng. Fract. Mech. 70 (2003) 839-851.

[7] P.S. Ambily, C. Umarani, K. Ravishankar, P. Ranjan Prem, B.H. Bharatkumar, Nagesh R. Iyer, Studies on ultrahigh performance concrete incorporating copper slag as fine aggregate, Constr. Build. Mater. 77 (2015) 233-240.

[8] A.S. El-Dieb, Mechanical, durability and microstructure characteristics of ultra-high-strength self-compacting concrete incorporating steel fibers, Mater. Des. 30 (2009) 4286-4292.

[9] M.K. Maroliya, C.D. Modhera, A comparative study of reactive powder concrete containing steel fibers and recron $3 \mathrm{~s}$ fibers, J. Eng. Res. Stud. I (2010).
[10] E. Worrell, L. Price et al. Carbon Dioxide from the Global Cement Industry, Energy and the Environment 26 (2001) 303-329.

[11] Xin Y., Zhong T., Tian-Yi S., Zhu P., Performance of concrete made with steel slag and waste glass, Construction and Building Materials, 114 (2016) 737-746.

[12] J.-H., Xie, Y.-C., Guo, L.-S., Liu, Z.-H., Xie, Compressive and flexural behaviors of a new steel-fibrereinforced recycled aggregate concrete with crumb rubber, Construction and Building Materials, 79 (2015) 263-272,

[13] M. Barbuta, M. Rujanu, A. Nicuta, Characterization of Polymer Concrete with Different Wastes Additions Procedia Technology, 22 (2016) 407-412.

[14] Celik T. Merer K. (1996). "Effect of crushed stone dust on properties of concrete, cement concrete" Res. 26(7), 11211130. 